University of Nebraska - Lincoln

DigitalCommons@University of Nebraska - Lincoln

Comparison of Two Perennial Grass Breeding Systems with Switchgrass

Kenneth P. Vogel

University of Nebraska-Lincoln, kvogel1@unl.edu

Vogel, Kenneth P., "Comparison of Two Perennial Grass Breeding Systems with Switchgrass" (2013). Publications from USDA-ARS / UNL Faculty. 1949.

https://digitalcommons.unl.edu/usdaarsfacpub/1949

This Article is brought to you for free and open access by the U.S. Department of Agriculture: Agricultural Research Service, Lincoln, Nebraska at DigitalCommons@University of Nebraska - Lincoln. It has been accepted for inclusion in Publications from USDA-ARS / UNL Faculty by an authorized administrator of DigitalCommons@University of Nebraska - Lincoln. 


\title{
Comparison of Two Perennial Grass Breeding Systems with Switchgrass
}

\author{
K. P. Vogel*
}

\section{ABSTRACT}

Two breeding systems, between- and withinfamily selection (BWFS) and multistep family selection (MFS), were compared using three switchgrass (Panicum virgatum L.) populations to determine which system was the most effective in improving biomass yield and in vitro dry matter digestibility (IVDMD). With BWFS, half-sib families are produced and evaluated on a family basis and then the best plants within the best families are selected for crossing to produce a new strain. With MFS, parent genotypes of the half-sib families being evaluated in the BWFS selection nursery are maintained and the genotypes whose progeny were the best in the BWFS evaluation trial are selected and polycrossed to produce a new strain. Methods were compared using two populations in which improved biomass yield and IVDMD were the selected traits and with a population for which improved IVDMD and winter survival were the selected traits. For the populations for which yield was a selection criteria, the BWFS breeding system produced strains with significantly greater biomass yields than the MFS system. For one of these populations, the BWFS and MFS systems did not differ for IVDMD but the MFS system produced a strain with higher IVDMD for the other population. For the population in which IVDMD and winter survival were the selection criteria, the BWFS strain had greater IVDMD than the MFS strain. Overall, the BWFS system was superior and required less work.
USDA-ARS, Grain, Forage, and Bioenergy Research Unit, 137 Keim Hall, Dep. of Agronomy and Horticulture, Univ. of Nebraska-Lincoln, Lincoln, NE 68583-0937. Mention of trade names or commercial products in this publication is solely to provide specific information and does not imply recommendations or endorsement by the U.S. Department of Agriculture. The USDA is an equal opportunity employer. Received 27 Sept. 2012. *Corresponding author (ken. vogel@ars.usda.gov).

Abbreviations: ADF, acid detergent fiber; ADL, acid detergent lignin; AWF, among- and within-family; BWFS, between- and within-family selection; DM, dry matter; $\mathrm{H}$, Mahalanobis distance; HSPT, half-sib progeny test; IVDMD, in vitro dry matter digestibility; MFS, multistep family selection; NDF, neutral detergent fiber; NIRS, near-infrared reflectance spectrometry; RRPS, restricted, recurrent, phenotypic selection; Syn, synthetic strain or population.

$\mathrm{P}$ ERENNIAL GRASSES such as switchgrass that are used for forage or biomass production reproduce sexually or asexually via apomixes or vegetative propagation. The agronomically important grasses that reproduce via sexual seed production with a few exceptions reproduce via cross pollination and are often selfincompatible (Vogel and Pedersen, 1993). This mode of reproduction restricts the breeding systems that can effectively be used to improve these grasses. Breeding methods that can be used on outcrossing perennial grasses have been described previously as well as their relative advantages, disadvantages, and the theoretical breeding gains that could be achieved with their use (Vogel and Pedersen, 1993; Casler and Brummer, 2008). However, there have been limited direct comparisons of the effectiveness of different breeding methods for perennial grasses in field trials.

Published in Crop Sci. 53:863-870 (2013).

doi: 10.2135/cropsci2012.09.0559

(C) Crop Science Society of America | 5585 Guilford Rd., Madison, WI 53711 USA

All rights reserved. No part of this periodical may be reproduced or transmitted in any form or by any means, electronic or mechanical, including photocopying, recording, or any information storage and retrieval system, without permission in writing from the publisher. Permission for printing and for reprinting the material contained herein has been obtained by the publisher. 


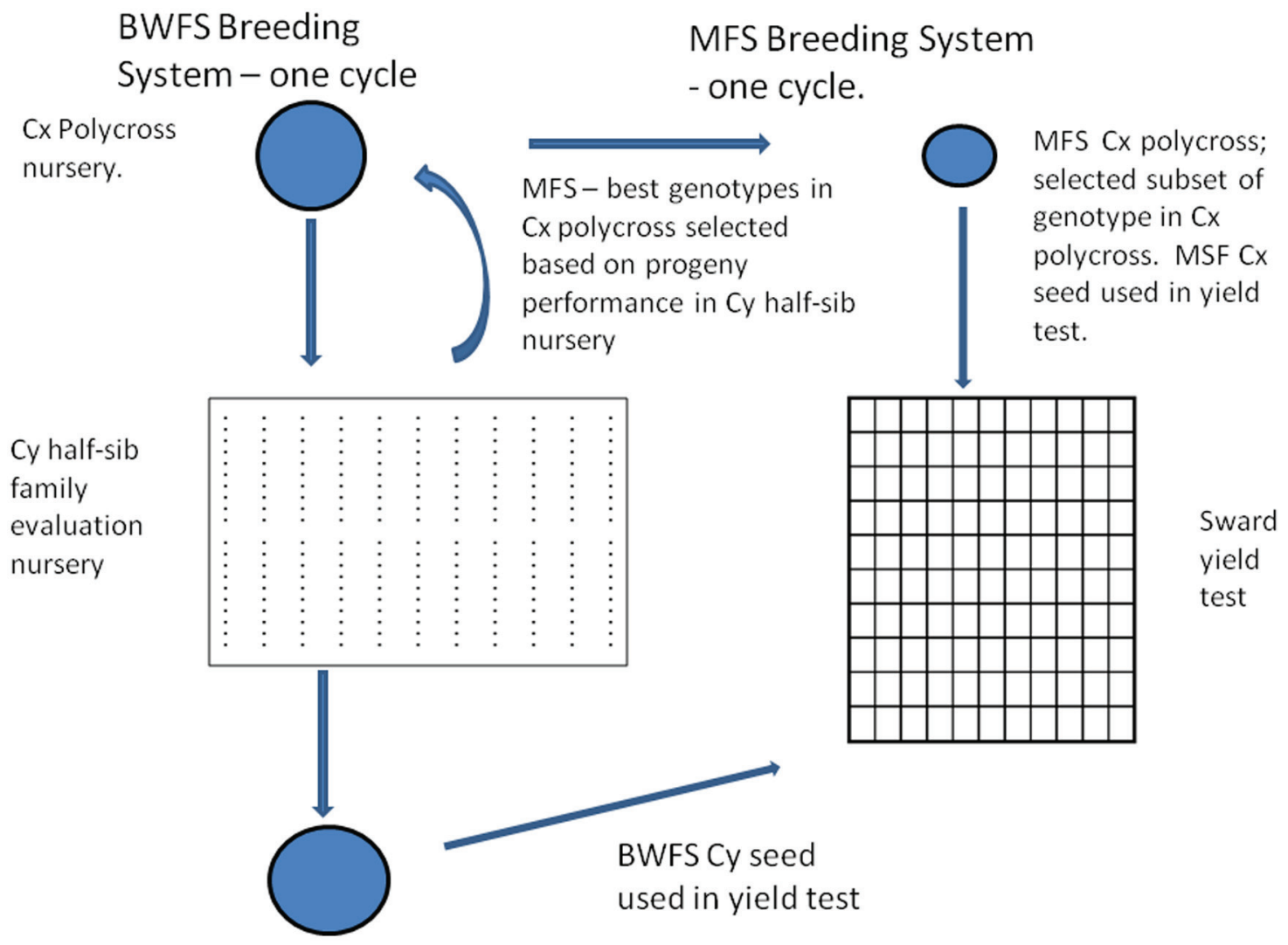

Cy polycross nursery; best plants from best families in Cy half-sib family evaluation nursery

Figure 1. Diagram comparing the between- and within-family selection (BWFS) and multistep family selection (MFS) breeding systems for perennial grasses. The " $\mathrm{C}$ " indicates breeding cycle and " $\mathrm{y}$ " and " $\mathrm{z}$ " designate generations. The Cz half-sib family evaluation nursery would be established using seed from genotypes in the Cy polycross nursery. Genotypes in the MFS Cy polycross would be selected from the Cy polycross nursery based on half-sib family performance in the Cz half-sib family evaluation nursery.

As pointed out by Vogel and Pedersen (1993) the most effective breeding methods for cross-pollinated, selfincompatible forage or biomass grasses are systems that do not require hand emasculation and exploit the perennial nature of the plants and their ability to be vegetatively propagated. Recurrent, population breeding systems meet these requirements and allow use of much of the additive genetic variation of the breeding populations. The primary breeding systems that have been used are the conventional half-sib progeny test (HSPT), restricted, recurrent, phenotypic selection (RRPS), and betweenand within-family selection (BWFS) (Vogel and Pedersen, 1993; Casler and Brummer, 2008). The HSPT was effectively used to develop the initial cultivars of many grass species but it was not effective in making additional breeding gains for several reasons (Vogel and Pedersen, 1993) and its use has been largely discontinued. The RRPS breeding method was effectively used to develop improved bahiagrass (Paspalum notatum Flüggé var. saurae Parodi) cultivars (Burton, 1989, 1992) and a switchgrass cultivar with improved forage digestibility (Vogel et al., 1991). However, RRPS was not an effective breeding method for improving biomass yield of switchgrass
(Hopkins et al., 1993) and its use in the USDA-ARS grass breeding and genetics project at Lincoln, NE, has been discontinued except as a method to select parent genotypes from newly formed or collected populations for initiating BWFS breeding populations.

Vogel and Pedersen (1993) proposed another breeding system, multistep family selection (MFS), which combines features of both the HSPT and BWFS systems (Fig. 1). In the MFS system, the parent genotypes used to produce the half-sib families in the next generation BWFS selection nursery are maintained. The half-sib family data from the BWFS selection nursery is used to select the best families in the nursery from which the best plants will be selected for polycrossing. The half-sib family data also is used to identify the parent genotypes in the previous polycross nursery whose progeny had the best performance in the BWFS nursery for the selected traits (Fig. 1). The MFS system when combined with the BWFS system thus produces two experimental strains each cycle. Vogel and Pedersen (1993) indicated that theoretically a strain based on a subset of the genotypes in a polycross nursery would have superior performance for the selected traits than a strain based on all the genotypes in the polycross nursery. 
Table 1. Experimental switchgrass stains produced by two different breeding methods, between- and within-family selection (BWFS) and multistep family selection (MFS), parent populations or check cultivars that were evaluated for biomass yield and quality in a seeded sward trial in eastern Nebraska during the period 2007, 2008, and 2009.

Cultivar or experimental strain and (breeding system) ${ }^{\dagger}$

\section{Pathfinder \\ Pathfinder YD C4 \\ (BWFS)}

Pathfinder YD N1 (MFS)

NE Late Syn YD C4

(BWFS)

\section{NE Late Syn YD N1 (MFS)}

Traillblazer

NE Trailblazer C4

NE Trailblazer C5

(BWFS)

NE Trailblazer C4 (MFS)

NE NB99Y (MFS)

NE 2000 C1

Shawnee
Strain description and breeding history $\ddagger$

Released upland, octaploid cultivar (Newell, 1968b)

Strain based on cultivar Pathfinder. Population was developed by three RRPS breeding cycles for high biomass yield $(\mathrm{Y})$ and high IVDMD (D) and one breeding cycle (C4) using BWFS for the same traits. A selection index (NI) was used, which gave equal weight to biomass yields and IVDMD. Based on eight plants selected from BWFS C4 selection nursery, which had 53 half-sib families (2 replicates each with 10 spaced plants per single row family plot).

Strain developed by selecting five genotypes from the 53 genotypes in Pathfinder YD C3 polycross nursery based on the biomass yield and IVDMD of their progeny in the Pathfinder C4 BWFS selection nursery. Selected plants were transplanted into an isolated polycross nursery and produced Syn 1 seed. Seed from the polycross was used to establish a 200 plant Syn 2 increase, which produced sufficient seed for the sward evaluation trial.

Population formed by intermating plants selected from Blackwell, Pathfinder, NE Type C, and NE Type D populations for high biomass yield and high IVDMD. The synthesized population was then taken through three cycles of RRPS and one cycle (C4) of BWFS for high biomass yields (Y) and high IVDMD (D) using a selection index (NI), which gave equal weight to biomass yield and IVDMD. Based on 14 plants selected from the BWFS selection nursery, which had 60 families half-sib families (2 replicates each with 10 spaced plants per family plot). NE Type C and NE Type D are northern type, upland octaploid populations originating from southern and northern Nebraska, respectively (Newell, 1968a). Blackwell is a southern upland, octaploid cultivar that originates from a collection made in northern Oklahoma (Alderson and Sharp, 1994).

Strain developed by selecting four plants from the NE Late Syn YD C3 polycross nursery based on the biomass yield and IVDMD of their half-sib progeny in the NE Late Syn YD C4 BWFS selection nursery. Selected plants were transplanted into an isolated polycross nursery and produced Syn 1 seed. Seed from the polycross was used to establish a 200 plant Syn 2 increase, which produced seed used in the sward evaluation trial.

Released cultivar developed by one cycle of breeding for increased IVDMD. Based on 13 EY and 12 FF plants (Vogel et al., 1991).

EY $\times$ FF C4 strain developed from the Trailblazer C3 population by using BWFS on 48 half-sib families for increased IVDMD and winter survival (Vogel et al., 2013). Based on 49 selected plants selected from the best families.

EY $\times$ FF C5 strain developed from the C4 population by BWFS on 49 C4 families for increased IVDMD and winter survival. Based on 10 selected plants that were polycrossed in isolation. Selection for IVDMD and winter survival of individual plants.

Population based on six C4 genotypes in the C4 polycross nursery, which were reselected on the basis of their progeny performance in the C5 selection nursery and moved to an isolated polycross and intermated to produce this strain. Selection was for IVDMD and winter survival.

Strain developed by selecting five genotypes each from the Pathfinder YD C3 and NE Late Syn C3 polycross nurseries whose progeny had the greatest biomass yields in their respective BWFS C4 selection nurseries. Two ramets of each selected genotype was transplanted into an isolated polycross nursery. Seed from the polycross was used to establish a 200 plant Syn 2 increase, which produced Syn 2 seed used in the sward evaluation trial.

Based on a population created in 1999 by selecting plants for high biomass yield and IVDMD using RRPS from Pathfinder HYLD C4 (17), IL 62 (13), NE 3 (6) and NE Late Syn HYLD C4 (10) selection nurseries. Selected plants moved to an isolated polycross nursery, which produced NE 2000 C1 seed used in the sward trial.

Released cultivar (Vogel et al., 1996)

${ }^{\dagger} \mathrm{C}$, breeding cycle or generation; D, selection was conducted for in vitro dry matter digestibility; N1, narrow base 1; Y, selection was conducted for biomass yield. ‡HYLD, high biomass yield; IVDMD, in vitro dry matter digestibility; RRPS, restricted, recurrent, phenotypic selection; Syn, synthetic strain or population.

However, it was not determined if the strain based on progeny tested parental genotypes (MFS strain) would be superior to the BWFS strain based on the best plants from the best families of the next generation BWFS nursery. The objective of this study was to make this comparison by using experimental strains developed from three different switchgrass populations.

\section{MATERIALS AND METHODS}

The two breeding methods were tested using three different upland, octaploid switchgrass breeding populations (Table 1). One population was based on the cultivar Pathfinder (Newell, 1968b), one population was based on the population from which the cultivar Trailblazer was developed (Vogel et al., 1991), and the other population (NE Late Syn YD) is based on a population with a broader genetic base. The previous breeding history of these populations and the specific experimental strains developed by the two breeding methods that were evaluated in this study are summarized in Table 1 . In the experimental strain name the letters "Y" and "D" indicate selection was conducted for biomass yield and in vitro dry matter digestibility (IVDMD), respectively, the "C" indicates the breeding cycle or generation, and "Syn" indicates that the stain is synthetic population. The check or control cultivars and experimental strain used in the evaluation trial are also listed.

\section{Breeding Nurseries}

The breeding and evaluation research was conducted at the University of Nebraska's Agricultural Research and Development Center, which is located $50 \mathrm{~km}$ west of Omaha, NE. All breeding selection nurseries were established by transplanting greenhouse grown seedlings into field selection nurseries on $1.1 \mathrm{~m}$ centers in rows. In the BWFS nurseries, family plots were rows 
of 10 plants. In the previous RRPS cycles, short rows of plants or sections of rows were used as the selection unit. Herbicides, rototilling, and hand weeding were used for weed control. After the establishment year, the nurseries were fertilized annually in the spring with a single application of $110 \mathrm{~kg} \mathrm{ha}^{-1} \mathrm{~N}$. Each spring, the between-row and within-row spaces between plants in the nurseries were rototilled with a tractor-mounted rototiller so that each plant occupied a $0.2 \mathrm{~m}^{2}$ mini-sward area at the start of each growing season. No data was collected the establishment year. For the BWFS selection nurseries, half-sib families were harvested on a plot basis for two postestablishment years. The results from these harvests was used to select the best families and then in the following year, individual plants within the best families were sampled and harvested on an individual plant basis for biomass yield and quality.

Nurseries were harvested in early August each year after panicle emergence. Biomass samples for quality analyses were collected with hand sickles with a cutting height of $10 \mathrm{~cm}$ before biomass yield harvests. For individual plant evaluation, four to five tillers were collected per plant while for family plot evaluations and one or two tillers were collected from each plant in a family plot. Biomass was harvested with a flail-type plot harvester with a cutting height of $10 \mathrm{~cm}$ after biomass quality samples were collected. The biomass quality samples were used to determine dry weight by drying them in a convection oven for $48 \mathrm{~h}$ at $50^{\circ} \mathrm{C}$. The dry matter (DM) concentration was used to determine dry weight yields per plant or plot. Sample dry weights were added to harvested plant or plot weights. Half-sib family plot dry weight yields were converted to biomass yields per plant by dividing plot yield by the number of surviving plants per plot. This was done because not all seedlings in transplanted plots survived the establishment year or survived all subsequent evaluation years. The nursery management for the polycross nurseries was similar to that for the selection nurseries.

The best plants within the best families were selected using the data from the individual plant harvests. Two ramets or clonal pieces of each selected plant were moved to an isolated polycross nursery where they were transplanted on $1.1 \mathrm{~m}$ centers in rows using a completely randomized design in spring of the year following the within-family evaluation harvests. In the first year of seed production, which was either the polycross establishment year or the following year, seed was harvested from individual plants in the polycross nursery and was bulked by genotype to produce half-sib families. Seed was then bulked across families to produce a bulk Syn 1 seed lot. In subsequent years, seed was harvested in bulk from each polycross nursery with a plot combine. The BWFS family polycross nurseries from the previous generation were maintained during the period in which the halfsib families produced by the nurseries were being evaluated in the next generation selection nursery. After the best families had been identified in the selection nursery, ramets of their female parent genotypes in the originating polycross were transplanted into a different isolated polycross nursery where they produced the seed of the MFS strain for that specific population. Because of the limited number of genotypes in the MFS polycross nurseries, it was necessary to use the Syn 1 seed to establish a Syn 2 seed increase nursery to obtain sufficient seed for use in the sward evaluation trial. The Syn 2 increase nurseries were established with 200 transplanted seedlings and were managed using the same procedures as for the polycross nurseries. The management practices for the polycross nurseries were similar to those for the selection nurseries except that they were burned each spring to remove the previous year's residue.

\section{Sward Evaluation Trial}

The experimental design of the sward trial used to evaluate the experimental strains produced by the two breeding methods was a randomized complete block with six replicates. Plots were 1.5 $\mathrm{m}$ wide and $3 \mathrm{~m}$ in length and were separated on the ends by a 1.5 $\mathrm{m}$ wide alley. The plots were seeded on 21 May 2007 at a rate of 370 pure live seeds $\mathrm{m}^{-2}$. The seeded plots were treated with quinclorac (3,7-dichloro-8-quinolinecarboxylic acid) $\left(0.56 \mathrm{~kg} \mathrm{ha}^{-1}\right)$ and atrazine (2-chloro-4-(ethylamino)-6-(isopropylamino)-striazine) (1.1 kg a.i. ha ${ }^{-1}$ ) pre-emergence after planting. The year after establishment, the previous year's residue was removed by burning. Nitrogen fertilizer was applied at the rate of $120 \mathrm{~kg} \mathrm{ha}^{-1}$. Stands were determined using a frequency grid at the time of spring greenup (Vogel and Masters, 2001). All plots had excellent stands in the spring of 2008 with almost no gaps in the seeded rows of each plot ( 7 rows spaced $0.18 \mathrm{~m}$ apart). The plots were harvested for biomass at the R3 stage of maturity (Moore et al., 1991) in August of each year using a flail-type forage harvester that cut a $0.9 \mathrm{~m}$ wide swath down the middle of each plot. The harvesting height was $10 \mathrm{~cm}$. Before harvest, approximately 10 tillers were sampled from four random locations with each plot. The samples were used for dry matter determination and for quality analyses. Yields are reported on a dry weight basis. Samples were taken to determine dry matter percent and for IVDMD, neutral detergent fiber (NDF), acid detergent fiber (ADF), acid detergent lignin (ADL), and total $\mathrm{N}$ analyses.

\section{Laboratory Analyses}

Switchgrass samples from the plots were dried in a $50^{\circ} \mathrm{C}$ oven for $48 \mathrm{~h}$ to determine DM concentration and then were ground through a $2-\mathrm{mm}$ screen in a Wiley mill and then reground in a cyclone-type mill to pass a 1-mm screen. Ground samples were scanned using a Model 6500 near-infrared spectrometer (NIRSystems [now FOSS NIRSystems, Inc.]) to determine feedstock composition and conversion. A set of switchgrass near-infrared reflectance spectrometry (NIRS) prediction equations for IVDMD, NDF, ADF, ADL, and $\mathrm{N}$ were used to determine the concentration of these biomass components. The procedures used to develop these calibrations are described by Vogel et al. (2011). The forage quality calibrations used in this study are based on a greater number of samples than those used by Vogel et al. (2011). The switchgrass NIRS forage quality calibrations are based on switchgrass samples that represented a wide range of plant maturities, cultivars, ecotypes, fertility rates, and environments. Calibration samples used to develop the prediction equations were analyzed in triplicate for IVDMD with the ANKOM Rumen Fermenter (ANKOM Technology Corp.) using the procedures described by Vogel et al. (1999). Nitrogen concentration was determined by the LECO combustion method (Model FP 428 and FP 2000; LECO Corp.) (Watson and Isaac, 1990; Bremner, 1996). Calibration samples were analyzed in duplicate for NDF and ADL with the ANKOM Fiber Analyzer (ANKOM Technology Corp.) using the procedures described by Vogel et al. (1999) and the ANKOM ADL procedure (ANKOM Technology-9/99, 
Table 2. Biomass yield, in vitro dry matter digestibility (IVDMD), other forage quality traits, maturity, and stand percentage means for experimental switchgrass strains produced using two different breeding systems on three switchgrass populations and check cultivars. Means are for the two postestablishment years, 2008 and 2009.

\begin{tabular}{|c|c|c|c|c|c|c|c|c|}
\hline Entry and (breeding system) ${ }^{\dagger}$ & Yield & IVDMD & NDF $\ddagger$ & ADF $\ddagger$ & $\mathrm{ADL}^{\ddagger}$ & $\mathrm{N}$ & Stage§ & Stands§ \\
\hline & $\mathrm{Mg} \mathrm{ha}^{-1}$ & & & $-\mathrm{g} \mathrm{kg}^{-1}$ & & 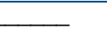 & score & $\%$ \\
\hline Pathfinder & 13.1 & 551 & 738 & 420 & 52 & 10 & 3.5 & 90 \\
\hline Pathfinder YD C4 (BWFS) & 14.0 & 563 & 724 & 409 & 49 & 10 & 3.4 & 90 \\
\hline Pathfinder YD N1 (MFS) & 12.8 & 560 & 735 & 417 & 51 & 10 & 3.5 & 93 \\
\hline NE Late Syn YD C4 (BWFS) & 15.7 & 548 & 740 & 421 & 54 & 8 & 3.4 & 93 \\
\hline NE Late Syn YD N1 (MFS) & 14.2 & 558 & 739 & 421 & 53 & 10 & 3.4 & 93 \\
\hline Trailblazer & 12.0 & 562 & 736 & 417 & 52 & 11 & 3.5 & 83 \\
\hline NE Trailblazer C4 & 11.6 & 580 & 733 & 409 & 49 & 11 & 3.4 & 86 \\
\hline NE Trailblazer C5 (BWFS) & 12.2 & 582 & 737 & 416 & 49 & 12 & 3.3 & 77 \\
\hline NE Trailblazer C4 (MFS) & 11.9 & 571 & 737 & 415 & 50 & 11 & 3.3 & 90 \\
\hline NE NB99 Y (MFS) & 13.9 & 553 & 732 & 419 & 53 & 10 & 3.5 & 90 \\
\hline NE 2000 C1 & 14.7 & 562 & 735 & 421 & 53 & 10 & 3.5 & 80 \\
\hline Shawnee & 15.7 & 552 & 719 & 405 & 53 & 10 & 3.4 & 100 \\
\hline Entry $F$ statistic & $8.67^{\star \star}$ & $54.59^{\star \star}$ & 1.64 & 2.07 & $3.89^{\star \star}$ & $8.62^{\star \star}$ & $2.92^{\star \star}$ & $5.78^{* \star}$ \\
\hline CV & 8.8 & 2.0 & 1.6 & 2.2 & 4.37 & 7.0 & 2.9 & 7.4 \\
\hline LSD 0.05 & 1.0 & 9 & $n s^{\pi}$ & ns & 2 & 1 & 0.1 & 5 \\
\hline LSD 0.10 & 0.8 & 8 & ns & ns & 1 & 0 & 0.1 & 4 \\
\hline
\end{tabular}

**Significant at the 0.01 probability level.

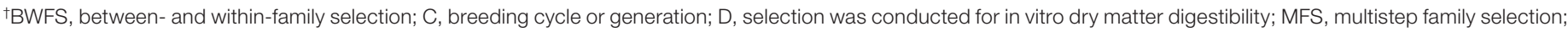
N1, narrow base 1; Syn, synthetic strain or population; $Y$, selection was conducted for biomass yield.

${ }^{\ddagger}$ ADF, acid detergent fiber; ADL, acid detergent lignin; NDF, neutral detergent fiber

$\S$ Stage is the maturity stage (Moore et al., 1991) at harvest in 2008. Stand percentages are for 2009.

"ns, not statistically significant.

Method for Determining Acid Detergent Lignin in Beakers). Laboratory means were used to develop calibration equations by partial least squares (Shenk and Westerhaus, 1991). The global H (Mahalanobis distance) statistic was used to compare the spectral profiles of the samples from this study with the samples used to develop the NIRS calibrations. Near-infrared reflectance spectrometry calibrations are considered to be fully valid for composition estimation when global $\mathrm{H}$ values are less than 3.0 (Murray and Cowe, 2004; Shenk and Westerhaus, 1991). The mean global $\mathrm{H}$ value for samples in this study was 2.9.

\section{Statistics}

The experimental data from the study was initially analyzed using a randomized complete block, split-plot in time ANOVA using Proc GLM of PC-SAS (SAS Institute, 2008). Years and replicates were considered random effects and the experimental strains and cultivars were fixed effects. The data set was balanced. The genotype (strain) $\times$ year interaction effect was not statistically significant for all analyzed traits so plot means over years were used in the subsequent analyses, which was a randomized complete block ANOVA using Proc GLM of PC-SAS. Plant stand percentages were analyzed using data only from the spring of 2009. Fisher's protected LSDs were used to make mean comparisons.

\section{RESULTS}

There were significant differences among the strains in the evaluation trial for all evaluated traits except for NDF and ADF (Table 2). The differences in maturity among strains using the staging system of Moore et al. (1991) were small.
Within population groups, differences in stands were not significant except for the Trailblazer based populations.

\section{Pathfinder Strains}

For the Pathfinder based populations, the BWFS strain (Pathfinder YD C4) had significantly greater $(P \leq 0.10)$ biomass yield and IVDMD $(P \leq 0.05)$ than the Pathfinder cultivar from which it was derived (Table 2). The improvement in IVDMD was accompanied by a small decrease in ADL. The MFS strain (Pathfinder YD N1) had significantly lower biomass yield and IVDMD than the Pathfinder YD C4 strain produced using BWFS (Table 2) and was lower in biomass yield than Pathfinder. The abbreviation N1 (narrow base 1) was used to identify the strains produced using the MFS breeding system. In the Pathfinder population, there were no benefits from using the additional breeding work of MFS in comparison to simply using the BWFS breeding system to develop an improved strain.

\section{Nebraska Late Maturity High Yield and In Vitro Dry Matter Digestibility Strains}

In the NE Late Syn YD population set, the strain produced using the BWFS breeding system (NE Late Syn YD C4) had significantly greater biomass yield $(P \leq 0.05)$ than the strain produced using the MFS breeding system (NE Late Syn YD N1) but had lower IVDMD $(P \leq 0.05)$. For this population set, seed of the earlier generations or the base population were not available for use in this study. 
The cultivar Pathfinder can serve as base reference for this population series because Pathfinder was one of the four populations used to synthesize this population and two of the other strains, NE Type C and NE Type D, were included in a strain evaluation trials (Newell, 1968a) in which Pathfinder (tested as Type F) was included and they had similar or lower yields than Pathfinder. The NE Late Syn YD population was developed to produce a breeding population for use in recurrent breeding systems with a broader genetic base than Pathfinder. The NE Late Syn YD C4 (BWFS) population had significantly greater biomass yield than Pathfinder and also significantly greater biomass yield than Trailblazer and was equivalent in biomass yield to the cultivar Shawnee (Table 2). It was equivalent to Pathfinder in IVDMD but had lower IVDMD values than the Pathfinder BWFS and WFS strains.

\section{Trailblazer Strains}

The Trailblazer based populations differ from the two previously discussed populations because biomass yield was not a selection criterion in their development. The cultivar Trailblazer was the $\mathrm{C} 1$ population in the series and was developed by a single RRPS cycle of selection for increased IVDMD (Vogel et al., 1991). In the first three RRPS breeding cycles, selection was only for increased IVDMD. Winter survival problems developed after the third breeding cycle (Vogel et al., 2002; Casler et al., 2002) so beginning with C4 generation, a BWFS breeding program was initiated in which the selection criteria were high IVDMD and winter survival measured by spring greenup percentages at least $3 \mathrm{yr}$ after the selection nursery was established. A full description of the development of NE Trailblazer populations and the evaluation of all the breeding generations in a space-transplanted population and half-sib family evaluation nursery has been reported separately (Vogel et al., 2013). In this study, the NE Trailblazer C5 strain (BWFS) had significantly greater IVDMD concentration than the NE Trailblazer C4 (MFS) strain but had a lower stand percentage and had equivalent biomass yield. Although there were differences among the strains in the Trailblazer population set, stands for all the Trailblazer strains and the strains in the study were above the frequency grid stand threshold $(\leq 50 \%)$ where stands begin to affect biomass yields (Schmer et al., 2006).

\section{Other Associated Strains}

The NE NB99 Y strain was a MFS breeding system derived population that was developed by selecting and intermating five genotypes each from the Pathfinder YD and NE Late Syn YD C3 polycross nurseries whose half-sib progeny had the largest biomass yields in their respective C4 BWFS selection nurseries (Table 1). It was developed and included in the study to test the effectiveness of combining plants from these two populations to produce a strain with improved biomass yield. In the evaluation trial, the NE NB99Y MFS strain had significantly less biomass yield than the NE Late Syn YD C4 (BWFS) strain and was equivalent to the NE Late Syn YD N1 (MFS) strain in biomass yield. The NE NB99Y (MFS) was equivalent to the Pathfinder YD C4 (BWFS) strain in biomass yield and had significantly greater biomass yield than the Pathfinder YD N1 (MFS) strain. Since the two populations belong to the same upland, octaploid heterotic group, these results match the theoretical expectations; that is, the mean of the progeny population is intermediate to the mean of the parent populations.

Another synthetic strain, NE 2001 C1, was also evaluated in this study. It was developed by combining genotypes selected for both high yield and high IVDMD from four different populations for which biomass yield previously had been the only selection criterion (Table 1). It was significantly lower in biomass yield than the NE Late Syn YD C4 strain and the cultivar Shawnee. At the time these populations were established, information on switchgrass heterotic groups was not available. It has subsequently been determined that the experimental populations and cultivars used to form this synthetic population all belong to the same octaploid, upland heterotic group (MartinezReyna and Vogel, 2008). It is not surprising then that the agronomic traits of these newly synthesized strains or breeding populations are approximately similar to the means of their parent populations.

\section{DISCUSSION}

The BWFS breeding system produced strains with greater biomass yields than the MFS breeding system for both the Pathfinder and the NE Late Syn YD populations for which biomass yield and IVDMD were the selection criteria. It is not known why the MFS strains had lower biomass yields. One potential, untested explanation is that for these upland switchgrass populations, there may be breeding population minimal sizes below which inbreeding effects can potentially affect biomass yields. In only one of the three populations, NE Late Syn YD N1 (MFS), did the MFS breeding procedure result in an improvement in IVDMD in comparison to the BWFS breeding system. The MFS breeding procedure requires more work than the BWFS because it is necessary to maintain the polycross nursery of the previous generation while the half-sib family progeny test trial is completed and an additional polycross nursery has to be established for intermating the selected genotypes (Fig. 1). If better methods for maintaining clones of perennial grass genotypes were developed such as cryopreservation rather than field isolations, then the MFS system could have value for some traits, but in general, it is not recommended for multitrait breeding for switchgrass in which yield is one of the selection criteria.

The BWFS breeding system combined with the previous RRPS breeding work with the Pathfinder and the NE Late Syn YD populations did produce strains that had higher biomass yields than Pathfinder, which can 
serve as comparison base for both populations as discussed previously. These improvements were achieved using space-planted selection nurseries in which each plant was maintained as a size-regulated mini-plot. The price of good quality grass hay in Nebraska and Iowa during the period 2010 through 2012 ranged from US $\$ 50$ to $\$ 200 \mathrm{Mg}^{-1}$ (USDA-Agricultural Marketing Service, 2013). Based on the average hay price during this period, the potential economic value of the breeding work to date to improve biomass yield with these two populations was $\$ 125 \mathrm{ha}^{-1}$.

The results of this study demonstrate that the BWFS system can be used to breed switchgrass for increased biomass yield and also increase or maintain IVDMD. Casler and Vogel (1999) have previously reported that a $\%$ increase in IVDMD can result in a $3.2 \%$ increase in average daily gain by beef cattle. The economic value of this improvement is dependent on both the price of cattle and the stocking rate and duration which are dependent on forage yield. Improvements made in IVDMD while increasing or maintaining biomass yield has economic value for livestock producers but are difficult to determine without data from grazing trials.

A smaller number of plants were selected from the NE Late Syn YD C4 and the Pathfinder YD C4 BWFS selection nurseries than what would typically be selected for use in a recurrent BWFS population in our breeding program (Table 1). To maintain adequate population size, a minimum of 50 plants are usually selected. A smaller number of plants was selected because the intent was to identify plants that could be used immediately to produce a potential new cultivar and to discontinue work with these populations per se because of the project's increased emphasis on cultivars for biomass energy production systems for which these populations are not well suited. If a breeder is interested in producing more than one experimental strain for testing from a BWFS selection nursery, a small set of elite plants could be selected from a BWFS for polycrossing to produce a testable elite strain. This would be similar to what was done in this study to produce the Pathfinder YD C4 and NE Late Syn YD C4 strains. A larger number of plants would need to be selected for continuing the recurrent breeding program and they also could be used to produce an experimental strain with a broader genetic base for testing.

For a large breeding program, developing and using populations in a BWFS breeding system from different heterotic groups would be useful both for the potential production of hybrid cultivars and for the development of limited generation synthetic cultivars. In the theoretical study by Casler and Brummer (2008) the BWFS breeding system is named the among- and within-family (AWF) system. In the BWFS breeding systems, the families are divided into two sets, selected and unselected, so I prefer the BWFS nomenclature. Regardless of which name is used, the BWFS breeding system is an effective breeding method for improving perennial grasses.

\section{References}

Alderson, J., and W.C. Sharp. 1994. Grass varieties in the United States. Agric. Handb. 170. Soil Conserv. Serv., USDA, Washington, DC.

Bremner, J.M. 1996. Nitrogen - Total. In: D.L. Sparks, A.L. Page, P.A. Helmke, and R.H. Loeppert, editors, Methods of soil analysis. Part 3. Chemical methods. SSSA Book Ser. 5. SSSA and ASA, Madison, WI. p. 1085-1121.

Burton, G.W. 1989. Registration of Tifton 9 Pensacola bahiagrass. Crop Sci. 29:1326. doi:10.2135/cropsci1989.0011183X00290 0050049x

Burton, G.W. 1992. Recurrent restricted phenotypic selection. Plant Breed. Rev. 9:101-113.

Casler, M.D., and E.C. Brummer. 2008. Theoretical expected genetic gains for among-and-within-family selection methods in perennial forage crops. Crop Sci. 48:890-902. doi:10.2135/ cropsci2007.09.0499

Casler, M.D., D.R. Buxton, and K.P. Vogel. 2002. Genetic modification of lignin concentration affects fitness of perennial herbaceous plants. Theor. Appl. Genet. 104:127131. doi:10.1007/s001220200015

Casler, M.D., and K.P. Vogel. 1999. Accomplishments and impact from breeding for increased forage nutritional value. Crop Sci. 39:12-20. doi:10.2135/cropsci1999.0011183X003900010003x

Hopkins, A.A., K.P. Vogel, and K.J. Moore. 1993. Predicted and realized gains from selection for in vitro dry matter digestibility and forage yield in switchgrass. Crop Sci. 33:253258. doi:10.2135/cropsci1993.0011183X003300020007x

Martinez-Reyna, J.M., and K.P. Vogel. 2008. Heterosis in Switchgrass: Spaced plants. Crop Sci. 48:1312-1320. doi:10.2135/cropsci2007.12.0695

Moore, K.J., L.E. Moser, K.P. Vogel, S.S. Waller, B.E. Johnson, and J.F. Pedersen. 1991. Describing and quantifying growth stages of perennial forage grasses. Agron. J. 83:1073-1077. doi:10.2134/agronj1991.00021962008300060027x

Murray, I., and I. Cowe. 2004. Sample preparation. In: C.A. Roberts, J. Workman Jr., and J.B. Reeves III, editors, Nearinfrared spectroscopy in agriculture. Agron. Monogr. 44. ASA, CSSA, and SSSA, Madison, WI. p. 75-112.

Newell, L.C. 1968a. Effects of strain source and management practice on forage yield of two warm-season prairie grasses. Crop Sci. 8:205-210. doi:10.2135/cropsci1968.0011183X000 $800020022 x$

Newell, L.C. 1968b. Registration of Pathfinder switchgrass. Crop Sci. 8:516. doi:10.2135/cropsci1968.0011183X000800040052x

SAS Institute. 2008. SAS 9.2. SAS Inst., Cary, NC.

Schmer, M.R., K.P. Vogel, R.B. Mitchell, L.E. Moser, K.M. Eskridge, and R.K. Perrin. 2006. Establishment stand thresholds for switchgrass grown as a bioenergy crop. Crop Sci. 46:157-161. doi:10.2135/cropsci2005.0264

Shenk, J.S., and M.O. Westerhaus. 1991. Population definition, sample selection, and calibration procedures for near infrared reflectance spectroscopy. Crop Sci. 31:469-474. doi:10.2135/ cropsci1991.0011183X003100020049x

USDA - Agricultural Marketing Service. 2013. NE-IA weekly hay review. USDA, Washington, DC. http://www.ams.usda. gov/AMSv1.0/ams. fetchTemplateData.do?startIndex $=1 \&$ te mplate $=$ TemplateW\&navID $=$ RN2HayL1\&rightNav1 $=$ RN2 HayL1\&topNav $=\& 1$ eftNav $=$ MarketNewsAndTransportatio nData\&page $=$ SearchHayReports\&result Type $=\&$ acct $=1 \mathrm{smn}$ (accessed 27 Feb. 2013). 
Vogel, K.P., B.S. Dien, H.J. Jung, M.D. Casler, S. Masterson, and R.B. Mitchell. 2011. Quantifying actual and theoretical biomass ethanol yields for switchgrass strains using NIRS analyses. Bioenergy Res. 4:96-110. doi:10.1007/s12155-010-9104-4

Vogel, K.P., F.A. Haskins, H.J. Gorz, B.A. Anderson, and J.K. Ward. 1991. Registration of 'Trailblazer' switchgrass. Crop Sci. 31:1388. doi:10.2135/cropsci1991.0011183X003100050080x

Vogel, K.P., A.A. Hopkins, K.J. Moore, K.D. Johnson, and I.T. Carlson. 1996. Registration of "Shawnee" switchgrass. Crop Sci. 36:1713. doi:10.2135/cropsci1996.0011183X003600060051x

Vogel, K.P., A.A. Hopkins, K.J. Moore, K.D. Johnson, and I.T. Carlson. 2002. Winter survival in switchgrass populations bred for high IVDMD. Crop Sci. 42:1857-1862. doi:10.2135/ cropsci2002.1857

Vogel, K.P., and R.A. Masters. 2001. Frequency grid - A simple tool for measuring grassland establishment. J. Range Manage. 54:653-655. doi:10.2307/4003666
Vogel, K.P., R.M. Mitchell, G. Sarath, H.G. Jung, B.S. Dien, and M.D. Casler. 2013. Switchgrass biomass composition altered by six generations of divergent breeding for digestibility. Crop Sci. doi:10.2135/cropsci2012.09.0542

Vogel, K.P., and J.F. Pedersen. 1993. Breeding systems for crosspollinated perennial grasses. Plant Breed. Rev. 11:251-274.

Vogel, K.P., J.F. Pedersen, S.D. Masterson, and J.J. Toy. 1999. Evaluation of a filter bag system for NDF, ADF, and IVDMD forage analysis. Crop Sci. 39:276-279. doi:10.2135/cropsci199 9.0011183X003900010042x

Watson, M.E., and R.A. Isaac. 1990. Analytical instruments for soil and plant analysis. In: R.L. Westerman, editor, Soil testing and plant analysis. 3rd ed. SSSA Book Ser. 3. SSSA, Madison, WI. p. 691-704. 